and over at their request or that of their general practitioner.

JULIETTA PATNICK

NHS Breast Screening Programme,

Trent Regional Health Authority,

Sheffield S10 3TH

JOAN AUSTOKER

Cancer Research Education Research Group,

University of Oxford,

Oxford OX2 6PE

1 Torgerson DJ, Donaldson C. An economic view of high compliance as a screening objective. $B M \mathcal{F}$ 1994;308:117-8. (8 January.)

2 Department of Health. The health of the nation. London: HMSO 1992.

3 NHS Breast Screening Programme. Breast cancer screening 1991 : evidence and experience since the Forrest report. Sheffield: NHSBSP, 1991.

\section{Anticoagulation in patients with atrial fibrillation}

EDrToR,-We were pleased that our brief paper on anticoagulation and atrial fibrillation generated considerable correspondence. ${ }^{2}$ Many of the points raised were dealt with in the longer paper that we submitted initially, but this was reduced to a short report. Clearly, the point that Saad M B Rassam makes about the validity of the trial results ${ }^{2}$ applies to all well controlled clinical studies in which participants are highly screened and closely followed up, as they were in the five trials of anticoagulation in atrial fibrillation. ${ }^{3-7}$ This does not, however, negate the importance of the trial results. ${ }^{8}$ No therapeutic progress would ever be made if we adopted such extreme views.

We were interested to learn that our finding of a low rate of anticoagulant treatment in patients with atrial fibrillation has been duplicated in general practice $^{2}$ and in another hospital. ${ }^{2}$ Clearly, purchasers should focus on this in the importan attempts now being made to reduce the number of strokes that occur in the community.

The question of age and treatment is always contentious. $^{2}$ The trials contained only a few subjects aged over 80 and hence do not give a clear answer on whether treating people with atria fibrillation in this age group is beneficial. Although there is no obvious reason why they should no benefit, the risks of anticoagulation are greater in older patients. For instance, patients aged over 80 who are receiving anticoagulation have an 8.5 -fold increase in the risk of major bleeding compared with subjects aged under $60 . .^{9}$ Another study suggests that the annual risk of cerebral haemorrhage in 80 year olds taking warfarin is $2-3 \%$, which is only just below the expected benefit of anticoagulation in reducing stroke. ${ }^{10}$

We agree that age is not an absolute contraindication, but we think that considerable caution should be exercised in prescribing warfarin to patients aged over 80 until further studies (including a meta-analysis of the five trials) describe adequately the ratio of risk to benefit for this intervention.

PHILIP M W BATH

Department of Medicine,

King's College School of Medicine and Dentistry,

London SE5 9PJ

MARTIN M BROWN

Division of Neuroscience,

St George's Hospital Medical School,

London SW17 0RE

GRAHAM A MACGREGOR

Blood Pressure Unit,

tt George's Hospital Medical School,

St George's Hospit

1 Bath PMW, Prasad A, Brown MM, MacGregor GA. Survey of use of anticoagulation in patients with atrial fibrillation. $B M Y$ use of anticoagulation in patie

2 Correspondence. Anticoagulation in patients with atrial fibrillation. $B M 7$ 1993;307:1492-4. (4 December.)

3 Petersen P, Boysen G, Godfredsen J, Andersen ED, Andersen B. Placebo-controlled, randomised trial of warfarin and aspirin for prevention of thromboembolic complications in chronic atrial fibrillation. Lancet 1989;i:175-9.

4 Boston Area Anticoegulation Trial for Atrial Fibrillation Investigea A The effect of low-dose warfin on the stroke in patients with nonrheumatic atrial fibrillation. $N$ Engl f Med 1990;323:1505-11.

5 Stroke Prevention in Atrial Fibrillation Investigators. Stroke prevention in atrial fibrillation study. Final results. Circulation 1991;84:527-39.

6 Connolly SJ, Laupacis A, Gent M, Roberts RS, Cairns JA, Joyner C. Canadian atrial fibrillation anticoagulation (CAFA) study. $f$ Am Coll Cardiol 1991;18:349-55.

7 Ezekowitz MD, Bridgers SL, James KE, Carliner NH, Colling CL, Gornick CC, et al. Warfarin in the prevention of stroke associated with nonrheumatic atrial fibrillation. $N$ Engl f Med 1992;327:1406-12.

8 Boysen G. Risk factors for stroke and effect of warfarin in nonvalvular atrial fibrillation: a pooling of data from five clinical trials. Neurology 1993;43:A390.

9 Landefeld CS, Cook EF, Flatley M, Weisberg M, Goldman L Identification and preliminary validation of predictors of major bleeding in hospitalised patients starting anticoagulation therapy. Am f Med 1987;82:703-13.

10 Gustafsson C, Asplund K, Britton M, Norrving B, Olsson B, Marke L-A. Cost effectiveness of primary stroke prevention in atrial fibrillation: Swedish national perspective. $B M$ 1992;305:1457-60.

\section{Gangliosides and the Guillain- Barré syndrome}

\section{No causal link}

EDITOR,-Gianluca Landi and colleagues report that 25 cases of the Guillain-Barré syndrome after treatment with gangliosides were seen over four and a half years in Italy, a yearly average of 5.6 cases. ${ }^{1}$ Their conclusion that these cases represent an excess incidence is incorrect. Their data estimate a yearly exposed population of roughly $2500000(4 \cdot 2 \%$ of the Italian population). The $5 \cdot 6$ cases represent a yearly incidence of $0 \cdot 2 / 100000$. Eleven of their patients were over 60 . The incidence of the Guillain-Barré syndrome is known to be higher in older age groups: an incidence of $3 \cdot 2 / 100000$ a year has been reported in people over $60 .^{2}$

We believe that it is inappropriate to compare the incidence of the Guillain-Barré syndrome in the normal population with that in patients selected for treatment with gangliosides-that is, patients with neuropathy - as the frequency of the syndrome seems to be increased in these patients. This is exemplified by surveys of referrals for generically defined neuropathy ${ }^{34}$ : on accurate examination $11-12 \%$ of the cases were diagnosed as cases of the Guillain-Barré syndrome. The syndrome may therefore be diagnosed in over $10 \%$ of patients with neuropathy (especially elderly patients), who potentially qualify for ganglioside treatment.

The authors have not exluded the possibility that gangliosides were prescribed for initial signs of a peripheral nerve disorder which was later identified as the Guillain-Barré syndrome. This would have introduced appreciable protopathic bias. More than half of the diagnoses recorded in patients receiving ganglioside treatment are compatible with early signs of the syndrome: distal paresthesia and sciatic pain, as well as facial nerve involvement, occur early in a considerable proportion of patients, and some patients experience a preceding episode of low back pain.

If treatment with gangliosides was an important aetiological factor in the pathogenesis of the Guillain-Barré syndrome the extensive use of these drugs in Italy should have influenced the incidence of the syndrome; this has not been recorded. The alleged risk of ganglioside treatment can be investigated only in well designed epidemiological surveys, such as Granieri et al's cohort study, which did not identify the Guillain-Barré syndrome in over 13000 patients exposed to the drugs. ${ }^{5}$

With regard to the therapeutic efficacy of gangliosides, several reports have described measurable effects of ganglioside treatment in controlled clinical trials in well defined disorders of the peripheral and central nervous system.

JC SAMSON

Infolife, 35121 Padua,

Italy

University of Brescia School of Medicine,

Brescia, Italy

1 Landi G, D'Alessandro R, Currò Dossi B, Ricci S, Simone IL, Ciccone A. Guillain-Barré syndrome after exogenous ganglioCiccone A. Guillain-Barré syndrome after exogeno
sides in Italy. BMf 1993;307:1463-4. (4 December.)

2 Beghi E, Kurland LT, Mulder DW, Wiederholt WC. Guillain Barré syndrome. Clinicoepidemiologic features and effect of influenza vaccine. Arch Neurol 1985;42:1053-7.

3 George J, Twomey JA. Causes of polyneuropathy in the elderly. Age Ageing 1986;15:247-9.

4 Halls J, Bredkjaer C, Friis ML. Guillain-Barré syndrome: diagnostic criteria, epidemiology, clinical course and prognosis. Acta Neurol Scand 1988;78:118-22.

5 Granieri E, Casetta I, Govoni V, Tola MR, Paolino E, Rocca WA. Ganglioside therapy and Guillain-Barré syndrome. A historical cohort study in Ferrara, Italy, fails to demonstrate an association. Neuroepidemiology 1991;10:161-9.

\section{Apparant association is a coincidence}

EDITOR,-Gianluca Landi and colleagues report the use of gangliosides and a series of 24 related cases of the Guillain-Barré syndrome in Italy between January 1989 and July 1993. I wish to provide further data on the alleged association between gangliosides and the syndrome.

In deriving the number of cases of the disease that would be expected to occur in chronological coincidence with use of the drug under the hypothesis of no association, the following should be considered. Firstly, both administration of gangliosides ${ }^{2}$ and the incidence of the GuillainBarré syndrome ${ }^{3}$ increase rapidly with age. Therefore, computations should be based on age specific incidences. Secondly, since the alleged association is postulated to have an immune mechanism ${ }^{4}$ the period at risk can reasonably be restricted to one month after use of gangliosides. ${ }^{45}$ In addition, as subjects may receive more than one therapeutic cycle during a given year it is appropriate to count each therapeutic cycle as the unit of exposure.

To compute the number of chronological coincidences expected to occur by chance alone I derived the age specific frequencies of therapeutic cycles of gangliosides (both mixtures and monosialoganglioside GM-1) for the entire Italian population from data for the years 1989-93.2 To them I applied the age specific incidences of the Guillain-Barre syndrome from two studies conducted respectively in Ferrara, Italy, ${ }^{3}$ and Olmsted County, Minnesota, United States. ${ }^{5}$ Because of the assumption of one month at risk after each exposure the average monthly incidence of the syndrome, obtained by dividing the annual figure by 12, was used (table). From January 1989 to November 1993 the total number of expected drug-disease coincidences was 24 with the figures for Ferrara and 35 with the figures for Olmsted County. The 24 cases of the Guillain-Barré syndrome in patients treated with gangliosides reported by Landi and colleagues were therefore equal to or lower than the number expected.

Although the numbers of treatment cycles used in these calculations is approximate and the case finding procedure followed by Landi and colleagues is hampered by many biases, their data do not suggest an association between use of gangliosides and the Guillain-Barré syndrome.

FRANCESCO GRIGOLETTO

University of Padua,

Institute of Hygiene,

35131 Padua,

Italy

1 Landi G, D'Alessandro R, Currò Dossi B, Ricci S, Simone IL, Ciccone A. Guillain-Barré syndrome after exogenous ganglioides in Italy. BMf 1993;307:1463-4. (4 December.)

2 Istituto Misurazioni Statistiche Italia. Studio prescrizioni mediche. Milan: IMSI, 1989-93.

3 Paolino E, Govoni V, Tola MR, Casetta I, Granieri E. Incidence 